\title{
A review of the book Problem-Solving and Selected Topics in Euclidean Geometry: In the Spirit of the Mathematical Olympiads, Springer, 2013, x+235 pp., ISBN 978-1-4614-7272-8
}

\author{
by Michael Th. Rassias
}

The present book contains a large variety of topics in Euclidean Geometry, which are examined in depth by a very rich collection of solved problems. At the beginning, a Foreword by the Fields Medalist Michael H. Freedman (University of California, USA) is featured. Initially, the authors present facts from logic and subsequently they survey upon the main methods of proof, namely proofs by analysis, synthesis, contradiction, and mathematical induction.

As the book progresses, fundamental aspects of geometric transformations (translations, symmetry, rotation, homothety, inversion) are studied andanalyzed through constructive examples.

Throughout the book, the definitions and theorems are very clearly presented. Basic theorems are presented with applications of different type. One could claim that going through the material of this lovely book is in a sense like reading a nice mathematical story. The theoretical facts studied in the book are applied in a large set of solved problems, most of which are completely original. The variety of different ideas developed in this problem-solving process is staggering. Some problems are very advanced and go even further than the olympiad caliber. Furthermore, the book contains a section devoted to geometric inequalities. An Index of Symbols and a Subject Index are given at the end in order for a better understanding and easy reading the book. 
The book is mainly directed to undergraduate students, high-school students who prepare for mathematical competitions, as well as to anyone who has a special love for classical geometry.

Cristinel Mortici

"Valahia" University, Târgovişte, Romania 